\title{
ÉDITORIAL
}

Franck Lefèvre

Président de la CARCDSF Vice président du CNAVPL

Adresse de correspondance CARCDSF - 50, avenue Hoche 75381 Paris

\section{LE PROJET DE RÉFORME DES RETRAITES EST AU CGUR DE L'ACTUALITÉ ET UNE GRANDE CONFUSION SE RÉPAND DANS LES ESPRITS}

C ertes, le Président de la République avait promis dans son programme la mise en place d'un régime universel de retraite devant apporter clarté, lisibilité, équité, et confiance pour les jeunes générations, mais après deux ans de concertation, le Haut Commissaire a présenté un projet de régime unique presque totalement étatisé auquel tous seraient avisés de se rallier car porteur d'un " avenir radieux ".

II n'a jamais été question pour les Chirurgiens-Dentistes de se recroqueviller sur un corporatisme étroit et nous avons fait nôtres les principes de lisibilité, d'équité et de simplification qui sous tendaient ce projet.

Toutefois, au fur et à mesure que le Haut-Commissaire dévoilait son projet, il nous est apparu qu'il nous était pour le moins très défavorable comme d'ailleurs à l'ensemble des Professions Libérales.

Le Haut-Commissaire a alors proposé des "chemins de convergences " différents pour chaque profession, chemin devant mener à terme vers une " cible " commune à tous les Français.

Devant l'iniquité patente et même l'impossibilité pour certaines Professions Libérales $\mathrm{d}^{\prime}$ augmenter leurs cotisations, les rédacteurs du projet ont proposé très récemment de baisser l'assiette sociale servant de référence à nos cotisations et enfin de baisser nos cotisations CSG pour nous permettre d'acquérir plus de points dans le régime universel.

Nos actuaires peinent à suivre la cadence imposée par les modifications de dernière minute censées amadouer les Professions Libérales. 


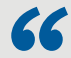

Nos actuaires peinent à suivre la cadence imposée par les modifications de dernière minute censées amadouer les Professions Libérales.

Les opinions émises n'engagent que leurs auteurs.
Les derniers rebondissements concernant les dates d'entrée dans le Régime Universel en fonction des années de naissance et la cohabitation provisoire des différents régimes ainsi que l'introduction d'un âge pivot compliquent encore l'analyse, et que dire du sujet des réserves constituées au prix d'efforts des cotisants et des allocataires pour lesquelles le Président dit qu'elles appartiennent aux Caisses mais dont le projet du Haut Commissaire calcule à sa façon une forte part devant échoir au futur Régime Universel et reste flou sur les possibilités d'usage de la part nous restant dévolue.

En définitive, nous assistons à un choc d'illisibilité doublé d'un choc de complexification et la démission de Jean-Paul Delevoye remplacé par un député sans expérience politique n'est pas de nature à permettre de revenir à plus de raison.

En l'état, ce projet ne peut convenir aux Chirurgiens-Dentistes car le risque est grand de voir le fruit de nos efforts passés se diluer dans régime unique et étatisé.

Le discours d'Édouard Philippe prévoit une loi votée cet été qui tracera les lignes directrices de la réforme et renvoyant à des ordonnances et des décrets la détermination de nombreux éléments techniques non encore définis.

L'ensemble des Professions Libérales s'accorde sur la conviction qu'un régime universel reprenant les promesses du Président de la République est possible à conditions que ce soit un régime universel de base calculé sur la base d'un plafond de la sécurité sociale, soit environ $40000 €$.

II permettrait d'embarquer les régimes spéciaux sans faire table rase de nos régimes complémentaires qui ont été sérieusement construits et gérés sans jamais coûter un euro à l'État. 